\title{
How Fair Is Actuarial Fairness?
}

Landes, Xavier

Published in:

Journal of Business Ethics

DOI:

10.1007/s10551-014-2120-0

Publication date:

2015

Document version

Early version, also known as pre-print

Citation for published version (APA):

Landes, X. (2015). How Fair Is Actuarial Fairness? Journal of Business Ethics, Vol. 128(no. 3), 519-533. https://doi.org/10.1007/s10551-014-2120-0 
Running head: Actuarial Fairness

Title: How Fair Is Actuarial Fairness?

Xavier Landes, University of Copenhagen, xavier.landes@gmail.com

\title{
This version is the author's version. The final publication is available at http://link.springer.com/article/10.1007\%2Fs10551-014-2120-0
}

\begin{abstract}
Insurance is pervasive in many social settings. As a cooperative device based on risk pooling, it serves to attenuate the adverse consequences of various risks (health, unemployment, natural catastrophes, and so forth) by offering policyholders coverage against the losses implied by adverse events in exchange for the payment of premiums. In the insurance industry, the concept of actuarial fairness serves to establish what could be adequate, fair premiums. Accordingly, premiums paid by policyholders should match as closely as possible their risk exposure (i.e. their expected losses). Such premiums are the product of the probabilities of losses and the expected losses. This article presents a discussion of the fairness of actuarial fairness through three steps: (1) defining the concept based on its formulation within the insurance industry; (2) determining in which sense it may be about fairness; and (3) raising some objections to the actual fairness of actuarial fairness. The necessity of a normative evaluation of actuarial fairness is justified by the influence of the concept on the current reforms of public insurance systems and the fact that it highlights the question of the repartition of the gains and burdens of social cooperation.
\end{abstract}

\section{Keywords}


Cooperation; Expected Utility; Insurance; Fairness; Premiums; Responsibility

\section{Acknowledgements}

This research received the support of the Danish Council for Independent Research, project Public Insurance, Equality, and Efficiency (10-080448). This paper benefited from the comments of two anonymous referees of the Journal of Business Ethics, Axel Gosseries, Nils Holtug, Kasper Lippert-Rasmussen, Martin Marchman, Søren Midtgaard, Morten Nielsen as well as comments received at several occasions such as the seminar of the department of political science at Aarhus University, the CESEM seminar, the workshop on Insurance and Discrimination (University of Copenhagen) and the $7^{\text {th }}$ International Conference on Applied Ethics in Hokkaïdo. 
Insurance is an important mechanism of cooperation for modern industrialized societies. The principle is that individuals gather resources against risk. By doing so, they are said to "pool" their risks. Therefore, insurance is usually characterized as a risk-pooling device.

Fundamentally, insurance is a cooperative mechanism that transforms the significance and implications of random events by mutualizing risks and their adverse consequences. ${ }^{1}$

From an individual point of view, risks imply uncertainty. For instance, what is your chance (not the average probability of the population you belong to) of being run over by a car? Of being afflicted by cancer? Of becoming unemployed or outliving your personal savings? These questions cannot be answered at a strictly individual level. Individuals experience uncertainty regarding accidents of various sorts: disease, chronic pathology, economic downturn, death, and so forth. From a collective point of view, though, uncertainty can be converted into probabilities. In the case of car accidents, for instance, instead of pure uncertainty, I may know that I have 1:100 odds of getting involved in an accident and, perhaps, 1:1000 odds of dying. Risk pooling provides the opportunity to calculate the probabilities of a particular set of events. In return, the expected costs for such risks can be calculated and spread over the policyholders through premiums.

In that sense, insurance is about transforming uncertain adverse events with uncertain outcomes into statistical events with certain outcomes: the expected losses that the payment of the premiums reflects. Following Knightian terminology (Knight 1921), insurance transforms uncertainty into risk, which is beneficial for individuals since the future becomes reliable. However, insurance can only deliver its benefits (the reduction/suppression of uncertainty, the spread of the costs for risks over the insured population) under an assumption of actuarial accuracy, i.e. if the probabilities and losses attached to adverse events are precisely calculated. 
Stemming from this actuarial accuracy, a further, but different, argument common in the insurance industry stipulates that individuals ought to be charged premiums reflecting their risk profile for two reasons. On the one hand, if the structure of individual premiums does not reflect the variation in risk exposure among policyholders, the financial stability of insurance will be undermined due to the multiplication of opportunistic behaviours, namely moral hazard (some insureds will take more risks as a result of being cheaply covered) and adverse selection (the insurance will attract high ("good") risks and drive away low ("bad" risks as a result of premiums that are not in line with individuals' risk exposure). On the other hand, non-actuarial premiums lead to a distribution of the burden of risk coverage that is unfair because it does not reflect individual risk profiles. This is the common justification for actuarial fairness offered by the industry: individuals should pay premiums that reflect the risks they bring to the insurance pool.

As a concept appealing to a conception of fairness, actuarial fairness naturally attracts the political philosopher. The fact that the insurance industry defines a particular way of calculating individual contribution to a cooperative mechanism as 'fair' raises three questions.

(1) How to characterize actuarial fairness? The first section of the article tackles this question by collecting the sparse material on actuarial fairness present in the literature, mostly issued by the industry, to draw a rough image of the content of the concept of actuarial fairness.

(2) What is the fairness of actuarial fairness? The second section offers a critical discussion of the concept of actuarial fairness as defined and used by the industry. Several reasons why non-actuarial premiums might be unfair are evaluated, such as cost shifting and deception. It is then shown that the 'non alteration of expected utility' (or 'expected utility invariance') is the principle that closely captures the reason why non-actuarial premiums might be unfair. Finally, it is argued that individual responsibility, which is a central argument 
invoked by the insurance industry to justify actuarial fairness, is actually more a sideargument than a core component of actuarial fairness.

(3) Is actuarial fairness actually fair? Based on the precedent developments, the last section challenges three claims that are central to the concept of actuarial fairness.

(3.a) Individuals should pay for their own risks and only their own risks.

(3.b) When entering into a pooling device such as insurance, individuals expect to contribute only at the level of their own risks. And the corollary: if they don't, premiums are unfair.

(3.c) The fairness of the principle of expected utility invariance.

As a conclusion, we advance the idea that the discussion of the fairness of actuarial fairness unveils a more profound issue, common in the contractarian literature: how to distribute the costs and gains produced by a specific cooperative mechanism.

Finally, this article has two far-reaching ambitions: one political, another philosophical. The political ambition is to stimulate discussions, especially in regard to public policies, on the justifications for insurance practices either public or private. Because questions of the right contribution of policyholders and citizens to diverse insurance mechanisms are becoming central (e.g. for public pensions, national health insurance), it seems important to have a serious discussion about the very concept of actuarial fairness, which has a great influence on the debates that surround public insurance. ${ }^{2}$

The philosophical ambition is contained in the assumptions that such a discussion unveils. The concept of actuarial fairness raises probably one of the most fascinating issues in regard to social cooperation: what is the right scope for redistributing the gains and burdens of social cooperation? $?^{3}$ Should the distribution of gains and burdens be restricted to the participants of a given cooperative mechanism? Or should such a distribution be mitigated by other considerations? The issue that actuarial fairness unveils is an issue about moral 
entitlements concerning the social product of individuals cooperating with each other and, also, about the proper balance between efficiency and equity. In that direction, this article concludes by mentioning avenues of future research.

\section{Actuarial Fairness: The View from the Industry}

Actuarial fairness is the guiding principle of the insurance industry. It constitutes the core justification for underwriting practices (i.e. risk classification) ${ }^{4}$ and legitimates the freedom (or right) to underwrite, which is the right of insurers to screen applicants, on criteria they find relevant, to determine their risk profile and either charge them premiums that track these criteria or refuse to insure them. The fundamental idea is that "fairness means equal treatment for equal risks" (Leigh 1998, p. 33) or, in other words:

"An insurance rate structure will be considered to be unfairly discriminatory...if, allowing for practical limitations, there are premium differences that do not correspond to expected losses and average expenses or if there are expected average cost differences that are not reflected in premium differences.” (Williams quoted by Hoy and Ruse (2005, p. 229)) Premiums should be calculated on the expected losses (the product of the probabilities of adverse results and their expected amplitude). From an insurer's view, actuarial fairness implies that "we are morally obliged to make sure that premiums for insurance of any type reflect the risks of the insured" (Daniels 2004, p. 124, emphasis added). This is interesting because actuarial fairness is presented as an obligation that goes beyond efficiency (to equilibrate the assets and liabilities) and extends to morality. Then, underwriting becomes the vehicle for achieving fairness.

"In insurance underwriting [unfair discrimination] occurs when equal risks are treated differently. In other words, it occurs when no sound actuarial justification or reasonably anticipated claims experience can justify the manner in which risks are classified', or 
when an underwriter misclassifies a risk because a relevant piece of information is kept from consideration.” (Meyer 2004, p. 31)

The purpose of underwriting is to classify risks. "Risk classification based on medical underwriting lies at the core of the existing voluntary, private life insurance business" (Meyer 2004, p. 27). Risks are not assessed on a strictly individual basis though. Instead, individuals are sorted into risk categories (class rating) according to diverse criteria (demographics, personal history, genetics, and so on) and charged premiums that reflect the average risk profile of their class.

Actuarial fairness stipulates that individuals should assume, through adjusted premiums, the costs of the risk that they "import" to the insurance pool. A simple example makes this idea compelling. Imagine that ten merchants who operate vessels for trading overseas decide to pool their resources for facing losses. The value of each individual shipment is $€ 1,000$ and, a priori, the probability of losing a shipment is .10 . So, the fair premium to impose on policyholders is $€ 100$. Now, imagine that five merchants have bought defective vessels that have twice the chance of wreckage. If premiums remain the same, it will be impossible to indemnify all the unlucky merchants, without undermining the solvency of insurance, since the collected resources will be insufficient to cover the losses. Actuarial considerations are then used to recalculate the premiums.

However, the actuarial adjustment may be implemented in different manners with a disparate impact on the policyholders. For instance, the premiums paid by all policyholders might be increased by $€ 50$. The new premiums (€150) are actuarially sound in the sense that they account for the general increase in risk exposure for the whole population. But they are also actuarially unsound because they do not account for the structure of risk profiles present in the pool, i.e. the distribution of risks among individuals. More importantly, they are actuarially unfair: merchants who operate non-defective vessels pay premiums not related to 
their risk profile. Therefore, they de facto subsidize merchants who own defective vessels. Another possibility is to maintain the same premiums for the former $(€ 100)$, but to double the amount paid by the latter (€200). Precise underwriting is indispensable for adequately discriminating individuals according to their risk exposure, re-assessing probabilities and losses, and calculating new fair premiums. This is the only actuarially fair solution since everyone is paying for premiums that reflect their risk profile.

Therefore, actuarial fairness requires proper risk evaluation and risk classification. When such requirements are not met, i.e. when underwriting is not or cannot be accurately done, resources are transferred from the low risks to the high risks. In other words, the mechanism of insurance changes policyholders' expected value ${ }^{5}$. In this sense, insurance is actuarially unfair because the expected utility of the low-risk individuals is reduced while the expected utility of the high-risk individuals is increased. However, and here is the point, it remains to be proven that "something" is unfair about non-actuarial premiums.

Fairness is a central concept of insurance theory and practice, especially when it comes to underwriting: "the process of risk classification serves insurers, policy holders, and applicants for coverage (or proposed insureds) by perpetuating financial soundness and fairness" (Meyer 2004, p. 29, emphasis added). Fairness directly relates to the moral ideal of insurance as seen by the industry. According to this view, "risk classification ensures that all of an insurer's applicants and existing policyholders are treated fairly" (Meyer 2004, p. 31, emphasis added). "To avoid unfair discrimination and to treat all applicants and all existing policy holders fairly, insurance companies must set premiums at a level consistent with the risk represented by each proposed insured" (Meyer 2004, p. 31, emphasis added). So, the question remains: why are non-actuarial premiums unfair?

\section{Actuarial Fairness: Formulating Unfairness}


At first sight, the reason why non-actuarial premiums may be unfair seems to have something to do with cost shifting. Since it is unfair for some individuals to bear costs stemming from the actions of others, non-actuarial premiums are unfair. But in this section, we demonstrate that not all instances of cost shifting may be objectionable. For insurance, the alteration of the expected utility is morally problematic because it is unfair. We then discuss the reasons why such alteration is unfair. This section closes with a discussion of the issue of individual responsibility, which is regularly invoked to justify the strict application of actuarial principles to the calculation of policyholders' contributions to the insurance pool. We demonstrate that individual responsibility is a side-argument that has little to do with actuarial fairness and, consequently, cannot be used to explain on normative grounds why non-actuarial premiums are unfair.

\section{2.a Cost shifting}

Individuals should pay for their own losses and only their own losses. Therefore, any cost shifting from one policyholder to another is unfair. ${ }^{6}$ In the case of non-actuarial premiums, some policyholders pay for the costs incurred by those whose risks have been underevaluated. The latter "externalize" their costs onto the former (Heath 2007). ${ }^{7}$ As a factory that dumps toxic products in a river imposes negative externalities, i.e. costs, on riverside inhabitants, non-actuarial premiums allow high risks to transfer part of their costs to low risks. In short, when high risks join an insurance that does not abide by strict actuarial principles, they create an externality for low risks, which is materially prejudicial and morally objectionable for the latter.

The argument may be understood in two manners. A radical version is to judge that any cost shifting among individuals involved in a cooperative mechanism is unfair. A milder 
version is to advance that only certain forms of cost shifting are unfair, the central point being about the conditions of the (un-)fairness of cost shifting.

(1) Interpreted as a critique of cost shifting in general, the argument is too radical. Many cooperative arrangements are precisely built on cost shifting without being unfair to any party in the exchange, like Credit Default Swaps $(\mathrm{CDS})^{8}$. In risk-shifting arrangements, an agent $\mathrm{A}$ promises to assume a loss that could occur to an agent $\mathrm{B}$ in exchange for a fixed or recurring payment. ${ }^{9}$ In the case of a CDS, more than shifting his costs to A, B swaps a potential loss (the structure of the expected losses he faces) for a determined one (the compensation paid to A). For his part, A receives a determined payment in exchange for an expected loss.

The shift of the expected losses from B to A is not unfair because A agrees to such a transfer beforehand and receives a payment for it. If A had not agreed to the cost shifting, it would have been unfair for him to bear the risk-induced losses. It is precisely the reason why negative externalities are unfair: a third party (the agent who bears the cost of the externality), who was not a part of the original exchange that produces the externality, never consented to the shift of costs. When a factory spills toxic chemicals in a river as a result of the production process, the costs incurred by riverside inhabitants are externalities, and they are usually presumed to call for redress or compensation. The unfairness of externalities does not stem from cost shifting per se, but from the fact that the cost was imposed on someone without his consent and/or without him benefiting from it. Imagine that the factory negotiates a monetary compensation beforehand with inhabitants for the right to pollute; costs will still be shifted, but in virtue of an agreement and a compensation. ${ }^{10}$ It is difficult to see anything inherently objectionable in this arrangement.

This version of the cost-shifting argument is also too radical regarding its consequence for the very principle of insurance as a risk-pooling device. It should lead to the conclusion 
that the principle of insurance is unfair since insurance is precisely about that: ex post shifting of losses from the lucky (low-risk individuals) to the unlucky (high-risk individuals). Thus, objection to losses shifting per se does not only constitute the basis of the judgment of the unfairness of non-actuarial premiums; it actually provides an argument against the principle of insurance in general. Furthermore, it would justify opposition to any freely negotiated arrangement according to which some agents face the material responsibility of others, such as CDS contracts.

In response to this objection, one may emphasize that insurance qua cooperative mechanism is not a risk-shifting but a risk-pooling mechanism. The difference would be that risk-shifting mechanisms lead to the transfer of the material responsibility from one agent to another, while, in risk-pooling mechanisms, all agents collectively remain responsible for the losses. (This collective responsibility is at the core of private entities like insurance companies, fraternal societies, unions, etc., and public institutions such as the state and other agencies and local bodies.) Therefore, it would still be legitimate to consider that a given insurance arrangement is fair if it does not lead to cost shifting.

This response underlines that the common confusion between risk shifting and risk pooling ${ }^{11}$ obscures the fact that, in risk-pooling mechanisms, policyholders do not assume the costs incurred by other policyholders. In fact, as the rest of the article discusses, they only bear a specific kind of costs: the expected losses. As a matter of consequence, it still makes sense to consider that a certain kind of cost shifting within a risk-pooling device is unfair and should be prevented. In an insurance properly conceived, individuals still pay for their expected losses (that are not shifted) even if the mechanism in practice consists, at a given time, of drawing resources from the pool, i.e. from the lucky policyholders, to compensate the unlucky ones. But, in the long run, all policyholders are supposed to pay only for their own costs. 
Transfers that take place in an insurance that is supported by fair premiums might look like cost shifting only in the short run. In the long run, however, policyholders pay for their costs and only for their costs: they pay for their expected losses. The unfairness of nonactuarial premiums is that costs are shifted in both the short and long run, which alters the expected losses of policyholders. What is objectionable is not the snapshot where current losses are spread over all policyholders, but the more distant picture where some policyholders gain at the expense of others. This is the basis of the softer version of the shifting-cost argument, which objects to situations where individual expected utilities $^{12}$ are changed by insurance, some gaining what others are losing.

(2) The moderate version of the cost-shifting argument sees an issue of fairness only in certain forms of cost shifting. Additional conditions need to be met to turn loss shifting into unfair loss shifting. The infringement of prior entitlement or an initial agreement may be one of those. In other words, it is only when loss shifting violates either the very general principle under which insurance as a pure risk-pooling mechanism is presumed to operate or the intention of agents at the moment they enrolled in such a cooperative device that it might be considered to be unfair. Since insurance as risk pooling is presumed to leave every policyholder with the same expected utility as when she enrolled, any modification of such expected utility indicates that something is potentially unfair.

To be sure, the unfairness of non-actuarial premiums does not actually lie in the shift of ex post (i.e. after the enrolment in the insurance) actual losses but ex ante expected ones. Said differently, the problem is not that individuals get compensated when risk occurs. The problem is that resources that are unfairly collected finance this compensation. The contribution to the insurance pool is unevenly distributed among policyholders. Some pay more than their risk exposure, while others pay less. The problem here does not lie in the shift 
of actual current losses but in the shift of the expected ones. ${ }^{13}$ Actuarial fairness then implies that enrolling in a risk-pooling device should not alter the expected utilities of policyholders.

\section{2.b Alteration of the expected utility}

A modified version of the cost-shifting argument thus stipulates that actuarial fairness consists in the non-alteration of individual expected utility. A situation is actuarially fair when each policyholder's expected utility remains unaffected by risk pooling. As insurance mechanisms reduce the standard deviation from the expected value (i.e. the "real" average), unfair premiums (i.e. premiums which diverge from strict actuarial calculations) generate situations where resources are transferred among policyholders. Stated differently, the mere fact of joining a risk pool financed by non-actuarial premiums modifies individuals' prospects of losses and gains. In order to avoid this situation, premiums should reflect the expected losses.

In the merchant example, if a flat rate of $€ 150$ is imposed on all agents, the expected utility of low-risk merchants is decreased by $€ 50$ (when comparing situations without and with insurance) when the expected utility of high-risk individuals is increased by $€ 50$. There is obviously a gain for some agents that is financed by others, outside of the general terms of the cooperative mechanism (insurance). Yet, the reason why the modification of the expected utility is unfair ought to be identified. Several reasons may be mobilized to prove that there is something wrong with the alteration of individuals' expected utility. However, this "something wrong" should be related to fairness. It is insufficient to demonstrate that the alteration of policyholders' expected utility raises a moral issue. It is necessary to prove that it raises a problem of fairness.

(1) A starting point is to cite deception as the reason why non-actuarial premiums are unfair: they would be deceptive for the low risks. As the argument goes, individuals enrol to be covered against risk. Since unfair premiums do not accurately reflect the distribution of 
risks among individuals, policyholders de facto participate in a redistributive mechanism (some policyholders' enhanced expected utility is financed by the decreased expected utility of other policyholders). Non-actuarial premiums would be unfair because they are deceptive: policyholders are misled about the real nature of the cooperative arrangement in which they participate. They think that they only pay for themselves when they also pay for risks brought to the insurance pool by other, riskier, policyholders.

On empirical grounds, deception would be facilitated by human epistemic limitations highlighted by the research on cognitive biases, heuristics and bounded rationality (Ainslie 2001; Ariely 2008; Kahneman 2011; Rubinstein 1998; Tversky and Kahneman 1974; Simon 1957; Stanovich 2009). In practice, it is very unlikely that individuals have an accurate (even adequate) knowledge of their risk exposure (contrary to the insurance company). The reason is that the nature and amount of the information needed is out of reach for a single individual. An individual risk profile is statistical data that refers to a given class, which means that it makes sense only according to the Law of Large Numbers ${ }^{14}$, i.e. on a large scale. Being aware of one's risk profile and, more importantly, being able to measure one's level of risk in monetary terms requires actuarial calculation on a large sample, something that is unattainable for most individuals. The epistemic context would thus facilitate deception.

One might, however, agree that non-actuarial premiums are deceptive but still remain sceptical that it has anything to do with fairness per se. It may be morally wrong without being unfair. Consider the following example. When distributing resources between Paul and Jane, an entity called "the great distributor" may promise to Paul that he will get all the resources. Afterward, "the great distributor" may change his mind and distribute these resources according to the respective needs or merits of Paul and Jane. Paul would have been obviously deceived (as would Jane), but “the great distributor's" final choice may arguably be fairer, everything considered. 
It is then possible to consider that non-actuarial premiums are not unfair from a redistributive perspective. An additional condition is needed. In the Jane-Paul example, the judgment of fairness (or unfairness) does not depend on the invariability of the initial rules, but on the final results. Stated differently, it might convincingly be objected that other considerations override the deception of individual expectations. Deception and unfairness then are two independent sets of considerations.

But it might be objected that fairness of outcomes is not the single conception available and that another conception will prove non-actuarial premiums unfair. In the guise of illustration, an alternative conception is rooted in what could be labelled as "the rules of the game" view: a state of affairs is fair if some particular constraints have been respected during the process that has generated this state of affairs ${ }^{15}$. A formulation of this view is provided by John Rawls when he writes that "the concept of fairness (...) relates to right dealing between persons who are cooperating with or competing against one another, as when one speaks of fair games, fair competition, and fair bargains" (Rawls 1958, p. 178). According to Rawls, the question of fairness arises in cooperative contexts in regard to the definition of the principles regulating the rules of cooperation and the repartition of the gains from cooperation. Fairness then bears not only on the outcomes; it also requires that participants freely abide by rules that are mutually and equally restrictive of their freedom.

In Rawlsian language, deception might be interpreted as arising when partners in a cooperative mechanism freely decide to follow original rules (the payment of expected losses) that, later on, turn out not to be the rules that the insurance plan actually follows (nonactuarial premiums) and, more, do not mutually and equally restrict the freedom of all policyholders (asymmetrical effects on expected utility). It is exactly what the non-actuarial premiums capture: premiums that are set at levels that allow some policyholders to extract a net benefit from the cooperative mechanism at the expense and without the consent of other 
policyholders (i.e. not everyone is subject to the same rules regarding the calculation of premiums). However, the core idea here is the non-respect of some initial contract among partners in cooperation; it is precisely what the idea of deception refers to: a change in the original, commonly agreed (at least hypothetically), terms of cooperation.

(2) Instead of situating the unfairness of the alteration of individuals' expected utility in deception, an alternative is to isolate the unfairness in the breach of the explicit or implicit contract between policyholders, i.e. the breach of the terms of cooperation. The unfairness of actuarially unsound insurance stems from the violation of what individuals agreed to or what it is reasonable to assume they might agree to. This does not rule out the possibility that nonactuarial premiums might also be deceptive. But, what primarily makes non-actuarial premiums unfair is the breach of an (hypothetical) initial agreement. In sum, policyholders agreed to be part of a cooperative mechanism, which is transformed into something different due to premiums that do not reflect one's expected losses. Furthermore, by way of consequence, non-actuarial premiums are a manner of relaxing the conditions for one side of the cooperation (high risks) while raising the bar for the other side (low risks).

Then, fairness has to be related, in one way or another, to the original expectations of the policyholders, i.e. the initial terms of the cooperative mechanism. This assumption is compatible with the view, widespread in the industry, that enrolment is a rational choice resulting from a cost-benefit calculation based on the initial elements (i.e. the terms of the insurance contract) given to the agents: “(...) individuals, when viewing such a voluntary transaction, make a personal determination if the cost of redistribution is worth the value of the benefit obtained by the insurance" (Lane, p. 143).

Non-actuarial premiums then lead to an alteration of individuals' expected utility. Policyholders subscribed to insurance in order to have their losses covered in exchange for the payment of a premium that should reflect their personal level of risk. Presumably, they did 
not agree to subsidize other policyholders, a point that is emphasized by the literature on insurance: "actuaries traditionally have argued that underwriting is justifiably unequal. This defense assumes that all forms of cross-subsidization are inherently wrong" (Moultrie and Thomas 1997, p. 129).

Unfair premiums violate the initial (implicit) agreement that establishes insurance and stipulates that no one should benefit from the insurance. Each policyholder should cover his risk and only his risk in expected terms. Individuals still gain by pooling their risks because it increases predictability in virtue of the Law of Large Numbers. This statistical reliability allows the redirection of pooled resources from period to period to those who experience a loss. If individuals expect to contribute at the level of their risk profile, but in reality contribute less or more than this level, insurance terms are not respected. Low risks then get less than what they expected to get, while high risks get more. Again, in addition to the initial terms of the contract, it is the very status of policyholders as equal participants in a cooperative mechanism who freely agreed to respect rules that are mutually and equally restrictive of all participants' freedom that is violated.

One way to express this point is to consider insurance as proposing to applicants to swap a lottery with various outcomes and probabilities for a certain outcome/loss. Unfair premiums pervert this offer by actually exchanging your lottery ticket for a loss that is higher than your expected losses if you are a low risk (or lower than your expected losses if you are a high risk). The unfairness is due to the transformation of the initial deal into something else.

This motivates the resistance to community rating within the insurance industry. ${ }^{16}$ As flat premiums are charged to high-risk as well as low-risk individuals, both classes contribute equally, but with diverging benefits. The latter receives less than the former for identical contributions to the insurance pool. To return to the merchant example, the imposition of flat premiums of $€ 150$ on all merchants increases the expected utility of the high risks (which 
moves up from $€ 800$ to $€ 850$ ) and, at the same time, reduces the expected utility of the low risks (which moves down from $€ 900$ to $€ 850$ ).

The idea that flat rates are unfair echoes the old view that unfairness resides in receiving more (or less) than “one's share”. In Politics (III.9) and Nichomachean Ethics (V.3), Aristotle gives a broad definition that has been the blueprint for more refined accounts proposed since: fairness is to treat equal people equally and unequal people unequally. In other words, fairness implies at some point an idea of equal treatment among individuals who share similar properties. To treat people fairly is not to treat all of them equally, but to introduce some distinction based on risk exposure.

Finally, the claim is widespread in the industry that the unfairness of non-actuarial premiums may be self-reinforcing through their incentive effect. As the argument usually goes, if premiums do not closely mirror policyholders' risk profiles, agents whose premiums are underestimated will have an incentive to adopt riskier behaviour, i.e. to personally benefit from the insurance beyond what they should. Since the actuarial costs of their risks are underestimated, it is rational for them to increase their risk exposure. They then adopt opportunistic behaviour and free ride on social cooperation.

Non-actuarial premiums would be conducive to moral hazard ${ }^{17}$, which seems unfair since some policyholders, in addition to contributing to the mutual risk coverage, pay for losses attached to actions that other policyholders have decided to undertake and, worse, which they have decided to undertake on a larger scale due to non-actuarial premiums. They subsidize other policyholders for worsening the situation of everyone else and extracting a benefit from the insurance. In that case, unfairness is located in the consequences of unfair premiums (in the absence of posterior adjustments of the premiums). Premiums that do not reflect risk profiles amplify the original unfairness. ${ }^{18}$ 
The background of the argument about the unfairness of expected utility alteration is the implicit reference to one's desert or merit (getting one's proper share) and the role that one plays in controlling one's risks (moral hazard). Low risks do not deserve to assume the costs of high risks, especially when the latter undertake riskier activities because their premiums are not actuarially sound. The implicit notion of risk property ("each policyholder should assume his own risk") and the opportunistic dynamics highlight the importance of individual responsibility, which is blatant in current debates on insurance, whether public or private. Before considering the notion of risk property, a few words are necessary on the actual role of individual responsibility in the concept of actuarial fairness.

\section{2.c Individual responsibility}

If we try to formulate the role played by the notion of individual responsibility in actuarial fairness, we might say that individuals should pay for the losses they are responsible for (i.e.

their expected losses and their expected losses only). ${ }^{19}$ Risks that are choice-dependent should be either underwritten more tightly (i.e. policyholders should pay higher premiums that reflect their degree of control) or, more simply, de-pooled (i.e. such risks should not be insurable in virtue of their dependence on policyholders' choices). Reversely, individuals should not pay for the losses they are not responsible for, i.e. for risks generated by other policyholders. Ronald Dworkin expresses a comparable idea with his analysis of expensive tastes (Dworkin 2002) and the distinction between voluntary and involuntary expensive tastes.

Imagine that a connoisseur of champagne cannot be satisfied with less expensive drinks like water, beer or regular wine. Should this connoisseur get compensated for his tastes? Dworkin's argument is usually thought to be a critique of welfarism, since if what matters for the distribution of resources is achievement in terms of welfare, the connoisseur of champagne should be given priority because the nature of his preferences requires him to use 
more resources to reach an equivalent subjective welfare than someone else. From Dworkin's perspective, the conclusion of the discussion of expensive tastes is that welfarism is not a terribly attractive moral position since it may lead to subsidizing individual preferences that are constitutive of life choices (i.e. voluntary expensive tastes). As it appears morally dubious to support the connoisseur of champagne for his costly habits, if he has chosen such habits, it appears morally dubious to support individuals for their risky behaviour, especially if it is the result of their choice.

In the same vein, unfair premiums force some policyholders to financially support other policyholders for the harmful or expensive consequences of their behaviour. As a means of illustration, young female drivers have traditionally paid lower premiums for motor insurance than young male drivers. The explanation is that they are less prone to have a car accident than male drivers in their first years of driving due to higher risk aversion that translates into safer driving habits, low consumption of alcohol and narcotics, and so forth.

However, the European Court of Justice ruled in March 2011 that using gender as a risk factor will constitute discrimination after December $21^{\text {st }} 2012 .{ }^{20}$ The insurance industry immediately denounced the 'unfairness' of the decision. The British Insurance Brokers' Association (BIBA) used car insurance to object to the decision: 'females will now pay a cross-subsidy for males on their insurance premiums' ${ }^{21}$ In addition to representing a subsidization of male drivers' choices, unfair premiums will give rise to opportunistic behaviours. Powerful vehicles will become more affordable to young male drivers, leading to an increased probability of accidents. And, last but not least, since insurance will be cheaper, young male drivers will become less risk averse.

This reaction from automobile insurers to the ruling of the European Court of Justice seem to be grounded on the idea that premiums are fair insofar as they only correlate to risks that fall under policyholders' responsibility. Therefore, the insurers' reaction gives the 
impression that it is unfair for policyholders to pay for risks that are unrelated to their responsibility. This fairness/unfairness cut based on individual responsibility can be justified by two arguments. Firstly, cross-subsidization would be unfair when it comes to risks that are choice-sensitive. Since car accidents heavily depend on one's driving habits, making other people pay for the careless behaviour of some is morally problematic. Secondly, such crosssubsidization would create moral hazard. In short, risks sensitive to choices rise if premiums are under-evaluated. As a result, additional losses would be pooled (since original premiums are actuarially unsound, it makes sense to presume that they will remain so), which implies that all policyholders will pay for the extra losses incurred by some of them.

This argument is not limited to gender discrimination for car insurance; health sector furnishes other examples. There have been numerous debates, in private and public sectors, about the unfairness of holding all policyholders responsible for health costs related to lifestyle diseases (or pathologies identified as such) like smoking-related cancers, obesity or, sometimes, AIDS (Daniels 1990). But the question arises: is the unfairness of non-actuarial premiums really located in the cross-subsidization of choice-sensitive risks such as motor vehicle accidents?

Under close scrutiny, the argument that tries to ground actuarial fairness on individual responsibility (in the sense that fairness would require policyholders to pay only for the costs that stem from risks they are responsible for) is inconsistent. In order to realize that, one should consider a case comparable to motor insurance, but where actuarial fairness justifies a completely different outcome: pensions. ${ }^{22}$

In the 1970s, the Department of Water and Power of the City of Los Angeles was charging differentiated premiums for its pension fund based on mortality tables. Since life expectancy is several years longer for females than for males, and pensions are an insurance against the risk of outliving one's retirement savings, women were charged higher premiums 
than men according to a reasoning identical to that used for car insurance, but with opposite results for women. A class action initiated by the female employees of the Department of Water and Power led the US Supreme Court to judge that the disposition infringed the 1964 Civil Rights Act (Title VII) 'which, inter alia, makes it unlawful for an employer to discriminate against any individual because of such individual's sex'. ${ }^{23}$

The case is interesting for three reasons. First of all, gender plays an opposite role than in motor insurance, which generates opposite, negative, intuitions about actuarial fairness. Then, the case shows that actuarial fairness can (and often does) clash with other intuitions one may hold about fairness (women, who are also vulnerable on labour markets, are imposed higher premiums for their pensions). Finally, it demonstrates that actuarial fairness obliges policyholders to assume costs for risks they are mostly not responsible for (life expectancy, i.e. the risk of outliving one's savings).

In the case of pensions, women are charged higher premiums because they live longer, on average, than men. Imposing flat rates in this case equates to making men finance women's longer retirement. It might seem unfair from the expected utility point of view, but the fairness/unfairness has nothing to do with individual responsibility since insurers have been traditionally eager to impose higher premiums for risks out of one's control (e.g. preexisting health conditions, genetics, etc.).

What is the exact importance of individual responsibility for actuarial fairness then? Actually, individual responsibility constitutes an independent consideration that is linked to moral hazard, i.e. to the ex post variance of probabilities and amplitude of losses. There is moral hazard because insurance is offered for risks over which individuals have some control and from which they might benefit. Nevertheless, moral hazard as a collective action problem has nothing to do with the fact that premiums are actuarially unsound, even if non-actuarial premiums may accentuate the alteration of individual expected utilities and so accentuate the 
incentive to benefit from insurance. Furthermore, if premiums are re-calculated after the emergence of moral hazard, there is no fairness issue anymore. Finally, moral hazard happens even in the presence of actuarially fair premiums (for example, all drivers drive faster with than without car insurance, no matter if their premiums closely reflect their risk profiles), which proves that it cannot be an argument in favour of actuarial fairness.

\section{Actuarial Fairness: Three Objections}

When considering why and how actuarial fairness could be fair, some arguments are more convincing than others. For instance, strict cost shifting and individual responsibility do not offer a strong basis for justifying for why strict actuarial premiums are fair. A better job is done by arguments centred on the idea that the alteration of the expected utility is unfair and, as a consequence, actuarial premiums (i.e. premiums that reflect risk exposure) guarantee fairness among policyholders. However, the fairness of actuarial premiums depends on second-order reasons, including the respect for the terms of the insurance contract and the status of the policyholders as participants in a cooperative mechanism who freely decide to abide by mutually and equally restrictive rules and principles. These reasons (among others) are salient for judging how fair actuarial fairness is.

Yet, the identification of actuarial fairness as based, at the first level, on the nonalteration of individuals' expected utility and, at the second level, on some kind of prior agreement about the nature of the cooperative mechanism leaves some issues untouched. Three in particular deserve to be mentioned since they bear on the application of actuarial fairness to the domain of public insurance.

nsert

Table 2

3. a Individuals should pay for their own risks, and only their own risks. 
The first question is about a notion that could be formulated as risk property. There are two understandings of what "one's own risks" could mean. According to a broad interpretation, “one's own risks" encompass all risks that happen to a specific policyholder. Any loss experienced by a given policyholder is, as a matter of fact, his, as is the risk (i.e. the anterior exposure to loss, without the obligation for such risk to occur) that underlies such loss. Therefore, the negative consequences should be underwritten in his insurance policy. According to a narrow interpretation, one's own risks encompass all risks that are, in some extent, related to one's actions, lifestyle, and so forth.

Some practices in the insurance industry seem to confirm the narrow interpretation. Car insurance covers risks that are related to driver habits and behaviours. Fire insurance compensates for risks that emerge following some misbehaviour or lack of care (regarding electric appliances or furnaces). Insurance against home robbery covers for risks that are usually avoidable by proper care (additional locks on doors, camera surveillance system, watch dogs, alarm, etc.).

However, the narrow interpretation is too restrictive. Many risks are actually independent from individual behaviour. In the case of health insurance, the industry charges individuals for their risk exposure, which is determined by individuals' lifestyles and other factors such as age, gender, location, family and personal antecedents, and so forth, so by factors that cannot be strictly connected with individual responsibility.

Another example is unemployment benefits. Unemployment may result from one's misbehaviour at the workplace or one's unwillingness to get a job, but, in our societies, it remains largely the consequence of the economic situation, so structural factors (such as the level of the aggregate demand and its repartition across the different sectors). Current high levels of unemployment are directly imputable, for the most part, to the economic downturn that followed the 2008 crisis. For an individual, being unemployed is his risk because it 
happens to him, but it is difficult to argue that it is his risk because it is directly and significantly produced by his choices or actions. More, it might be argued that the agents responsible for the current economic difficulties are some mortgage brokers, bankers, insurers, and regulators, but not most of the jobless people.

In that context, the expression of one's own risks mostly refers to the broad view where everything that might happen to an agent turns out to be his own risk. It is, however, one thing to locate a risk and another to attribute some material or moral responsibility for it. There are two questions here, the first about the attribution of risks to individuals, the second about the attribution of material responsibility for such risks. Actuarial fairness as commonly invoked by the industry tends to conflate these two dimensions considering that material responsibility directly derives from risk ascription.

So, to which extent and under which conditions are individuals materially responsible for what happens to them? Replying to this question is essential for judging the fairness of a given structure of premiums. So far, the rule of the attribution of the material responsibility of losses is incomplete in the mobilization of actuarial fairness in the industry. There is a missing link. As a last example: you are insured against fire, and your neighbour throws an incendiary bomb in your house. The resulting fire is your risk because it happens to you, but should the probability of receiving an incendiary bomb in one's house be accounted for in one's premiums? Imagine that your insurance forces you to have coverage for every kind of damage that might happen to me whatever the origin. Are the resulting premiums fair? The kind of reply one may provide to this question is contingent on a more or less explicit rule of risk ascription. But such discussion exceeds the scope of this article.

3.b When entering into a pooling device such as insurance, individuals expect to contribute only at the level of their own risks. If they don't, premiums are unfair. 
This statement expresses the view that situates the foundation of actuarial fairness in the original terms of social cooperation. However, what is the epistemological status of this statement? Do people actually expect to contribute only at the level of their own risks? Or should they be expected to expect to contribute only at the level of their own risks? Is it an empirical or a hypothetical claim? Indirectly, what is at stake here is the pretention of insurance to be rooted in a scientific approach, namely actuarial sciences. ${ }^{24}$

There are two ways - empirical and hypothetical - to understand this claim. The empirical view affirms that individuals do actually expect to contribute at the strict level of their risk exposure. It is a matter of fact and, as such, it is the basis of insurance, because having premiums that diverge from the expected losses constitutes either a deception or a breach of an initial (implicit) agreement. But, understood as such, the claim raises the question of the capacity of individuals to properly evaluate their risk exposure. If they experience difficulties carrying on such evaluation, they will not know the exact terms of the contract they agreed to. They will know how much they put in the insurance without knowing (and, so, being able to evaluate) how much this contribution actually reflects their risk exposure. More than their ability to commit themselves, it would undermine the moral value of their commitment. To determine if an actuarial calculation is fair, it would be necessary to ask each individual about his understanding of the terms of the insurance and compare the responses to the genuine terms of particular insurance contracts.

Another manner of understanding the claim is the hypothetical view. It stipulates that what individuals actually think or believe regarding the terms of the contract does not matter so much. When the premiums are based on accurate probabilities, they are fair anyway because individuals need to pay for their objective expected losses. In this case, people are expected to expect to contribute only at the level of their risk exposure. Such a comprehension raises three questions. 
Firstly, can the objective probabilities be incorporated in actuarial calculations? Which degree of objectivity is needed to turn premiums into fair ones? Not speaking about fairness for the moment, but about the very possibility of basing premiums on objective probabilities, consider the actuarial calculation for financial risks. In 2007, systemic risks (caused by the degree of interdependence between mortgage lenders, banks, insurers, re-insurers and corporations) as well as unpredictable risks (the famous "Black Swans" (Taleb 2008), i.e. risks with such low probabilities that they are not included in the risk assessment) were underestimated. This epistemological limitation had concrete and severe negative outcomes. For instance, insurance companies were far more exposed to risks than they thought they were because derivatives' markets were perceived to be much more stable than they were, etc. The crisis illustrates the uncertainty that remains in any probabilistic account and, consequently, in any insurance system. Concretely, it implies that individuals always pay, partly, for something that diverges in some respect from their objective, real, risk exposure because objective risk is inaccessible.

Secondly, how should class rating, a practice which is at the core of the industry, be regarded? Since the level of risk of a given individual cannot be exactly evaluated (everything is statistical, so calculated according to the Law of the Large Numbers), each individual pays for the risk exposure that characterizes the class to which he belongs according to his demographic and personal characteristics. As a consequence, he still pays for others' risks or receives a surplus from the contribution of other policyholders. So, the principle that premiums are fair as long as they strictly reflect one's expected losses should not be interpreted too strictly. Premiums cannot precisely reflect one's level of risk. Consequently, even hypothetically, individuals cannot be expected to expect to contribute at the level of their own risks. 
Thirdly, how to interpret the common practice among insurance companies to adjust premiums based on the kind of coverage selected by policyholders? By doing so, insurers do not track down so much one's "objective" level of risk (contrary to what is assumed by the theory of revealed preferences), but, rather, one's risk aversion, which is different. The dimension that is skimmed off in many discussions is that premiums not only reflect one's risk exposure, but also one's tolerance vis-à-vis uncertainty (no matter one's risk profile).

Thus, the view that stipulates that premiums are fair due to a hypothetical initial agreement should include this dimension. The implication is that there is not just one fair (ideal) solution when it comes to the calculation of premiums - the expected losses - but a variety of solutions with different levels of coverage that mirror different levels of risk aversion. It means that by looking at one's level of risk, an insurer cannot determine if the premiums that would be derived from it will be judged as being fair. Moreover, it stresses the idea that individuals cannot be, even hypothetically, expected to contribute at the level of their risk exposure only. Ultimately, it stresses an important dimension of insurance, partly disregarded by the industry: although the social benefit of insurance is to spread risks, it is also to curb the subjective feeling of uncertainty.

This awareness of the importance of risk aversion to the kind of arrangement individuals judge worthwhile raises a last question. Is it fair to make premiums dependent on one's risk exposure and risk aversion? A way to reformulate the question is to determine whether risk aversion represents a voluntary or involuntary expensive taste in the Dworkinian sense. The question is complex because it is not only about one's subjective tolerance of uncertainty, but also one's material capacity to handle potential losses. Individuals may subscribe to extra insurance for the very reason that they know that they will not be able to cope with the potential losses due to limited resources, where it may not be a problem for advantaged individuals (who do not subscribe to any extra insurance because they can handle 
the potential losses). In this case, do risk-averse policyholders still pay for their own risk or for something else too? Which is then the right level of additional premiums to levy on riskaverse individuals in order to keep premiums fair? Why is it fair to make someone pay for his risk aversion?

3.c The fairness of the principle of expected utility invariance.

The version of actuarial fairness discussed in these pages postulates that an increase in expected utility for some policyholders translates into an equivalent decrease in expected utility for other policyholders. Every gain or loss should be compensated within the system. It is a zero-sum game: the net benefit of some should be paid out of the pockets of others. The implicit assumption is that insurance is a non-productive cooperative arrangement, in comparison, for instance, to economies of scale that imply gains of productivity (Heath 2006a). ${ }^{25}$ Insurance would not add anything to or retrench anything from the world. It explains why the concept of actuarial fairness cannot tolerate net transfers, in the long run, among policyholders. Since the system is closed and no extra resource is generated, individuals take out of the insurance what they previously put in. Furthermore, to be completely fair, such an arrangement should lead individuals to take out what they put in (i.e. to have a level of coverage aligned with their contribution, which means their expected losses).

This formulation is far too restrictive. Even if we grant that insurance is not a productive arrangement per se in the sense that it does not directly produce any added value, it is nevertheless a cooperative arrangement that indirectly generates social benefits of various sorts. For instance, health insurance may increase labour mobility, which leads to a better allocation of the labour force throughout a given territory. ${ }^{26}$ Insurance creates additional resources. For instance, the fact that work accidents were covered by insurance promoted 
industrialization (Ewald 1986). Insurance incentivized entrepreneurs to invest in their factories, even if it led to more accidents.

Because insurance offers to some individuals the opportunity not to support the full costs of their actions, they undertake riskier but socially beneficial activities (e.g. trading overseas, starting businesses, becoming highly specialized). In other words, insurance removes, or at least reduces, a great deal of the uncertainty individuals face in their personal and professional lives, which renders courses of action that produce (collective) benefits that are usually overshadowed by (private) costs more attractive. Insurance transforms uncertainty into statistical risk that could be spread over the community, which is accompanied by various social benefits (Anonymized reference).

In this context where insurance as a cooperative mechanism produces gains for the participants themselves in terms of risk management, but also for the whole society in terms of increased wealth, industrial initiatives, scientific advances and so forth, the concept of actuarial fairness raises the political and philosophical problem of the distribution of the direct and indirect benefits incurred by insurance mechanisms.

Insurance produces positive externalities that, as externalities, are not accounted for when premiums are strictly calculated on the expected losses a given agent faces. ${ }^{27}$ Imagine that an agent's activities generate large social gains for which she is not fully retributed (e.g. Marie Curie). Furthermore, these activities may bear important potential losses for the agent (e.g. in terms of health costs for Marie Curie). In the absence of other sources of motivation, agents may have no reason to engage in socially beneficial, but individually hazardous, activities.

Insurance may either reinforce or alter this structure of incentives. In the case of strict actuarial premiums, the agent pays premiums that reflect her personal risk exposure, the share of the pooled resources she may need to use to cover her losses, but these premiums do not 
reflect the additional wealth, knowledge or collective benefits such an individual creates (e.g. Marie Curie's research on polonium and radium) for the enjoyment of other individuals. The heart of the matter is that by imposing premiums that strictly reflect one's expected losses, actuarial fairness overburdens activities that produce benefits which are distant in time or space, i.e. benefits on which their producers have no direct claim. The premiums imposed on her might be actuarially fair, but could they be considered as fair everything considered, especially because her activities improve the common lot, i.e. the resources others enjoy?

In addition to the unfairness of the situation (the agent is not recompensed for her socially beneficial activities), there is a more perverse and damaging effect. Since the producer of the externalities cannot enjoy the full benefits generated by her activities while having to cover the full expected losses, individual incentives are distorted. At the extreme, our agent may be forced to cease her activities due to too high premiums that she could not assume without collective subsidization of one form or another (for instance, non-actuarial, i.e. reduced, premiums). ${ }^{28}$

To summarize this third section, actuarial fairness is an incomplete conception under its own standards because it cannot account for objective risks. It is also a flexible conception in the sense that individuals do not pay for their strict risk exposure, while being subjective since the amount of premiums that may be considered as fair depends on individual risk aversion. Finally, it is a narrow conception that does not include the positive externalities generated by risky activities.

\section{Conclusion}

In the end, the discussion about actuarial fairness is a discussion of the criteria for determining whether a cooperative arrangement is fair or not, but also a discussion of the right (moral) perspective from where to judge such an arrangement. The previous pages have 
described a tension between two visions of fairness in different social settings, which is the subject of numerous debates in public policy.

On the one hand, the actuarial conception of fairness is based on considerations internal to insurance mechanisms (how to handle risks through a pooling device). Put differently, the only defensible normative position for evaluating a cooperative mechanism (e.g. insurance, trade, production) is to judge the social benefits of such a mechanism when operating under strict internal considerations (i.e. when insurance only aims at managing risks and nothing else) and how the gains and burdens are distributed within the mechanism itself. Considering that insurance is about pooling risks for increasing the statistical reliance (and allowing the calculation of probabilities and spreading of losses), it seems fair not to go astray of a strict pooling mechanism and distribution of costs according to expected losses (i.e. to turn this device into something else).

On the other hand, objections to actuarial fairness usually adopt a broader scope for determining whether an arrangement (i.e. a distribution of the gains and costs) is fair or not. Whereas the actuarial view tends to reduce fairness to the respect by the agents for their duties qua participants to the cooperative mechanism (insurance), the broader version presents a more demanding conception of fairness (like when Norman Daniels attributes to health insurance the task of preserving or guaranteeing the 'fair equality of opportunity' [Daniels 1990, p. 512]). Cooperative terms are fair if they respect principles and terms that are mainly external to the cooperative mechanism. Considering the importance of insurance in people's lives, it seems important to include considerations for the personal situation or the social environment when determining if a specific arrangement is fair. Consistent with this position is the view that the distant social benefits of insurance (the positive externalities) should be included in one's judgment about the fairness of a structure of premiums. 
This tension sheds light on the issue of the proper normative constraints to be imposed on specific cooperative devices. For instance, one may consider that insurance should abide by its own rules, i.e. by actuarial principles, for guaranteeing its efficiency (i.e. avoiding moral hazard or adverse selection). Furthermore, it may be argued that what is expected from any insurance is to cover adequately people against risks and, for that, it requires actuarial calculations and maybe charging people according to their own risk profile (expected losses) and only their own risk profile. In other words, the social value of insurance would stem from its efficiency at reducing uncertainty and spreading risks. As such, it would make the case for scrupulously respecting actuarial fairness in order not to disrupt the production of social benefits.

The issue of the fair terms of social cooperation runs through these pages: should insurance, as a particular cooperative arrangement, abide by its own rules or should it be subjected to more general rules of fairness? Actuarial fairness poses the question of the repartition of the costs and benefits of cooperation, not in general, but of a specific kind (risk pooling). It emphasizes the necessity to consider thoroughly three sub-questions during future research on insurance: (1) What is the original agreement to which individuals may reasonably be supposed to have adhered as policyholders? (2) How should individual responsibility mitigate each policyholder's contribution? (3) How should external benefits be allocated (to the cooperative mechanism)? Should they be left outside of the specific cooperative mechanism or internalized? In short, actuarial fairness raises the essential question of the conditions that define fair or just social cooperation.

\footnotetext{
${ }^{1}$ Any discussion of insurance should distinguish between insurance as the general cooperative arrangement among individuals based on risk pooling and specific arrangements where an insurer acts as an intermediary between policyholders. In other words, a distinction should be
} 
made between the concept and different conceptions of insurance. This article is mainly about the concept of insurance as a cooperative mechanism. Even if mentions are made of cases where an insurer acts as an intermediary, the locus of the article remains the philosophy of insurance, i.e. the normative principles that should prevail when individuals decide to pool their risks in the face of uncertainty. We are grateful to an anonymous referee who brought this point to our attention.

${ }^{2}$ Actuarial fairness as a topic of philosophical and normative enquiry is relatively underdeveloped, especially compared to fairness in redistributive justice, for instance. No matter how emerging, the ground-breaking works of various authors should be acknowledged here, in particular for their contribution to the analysis of insurance, underwriting and actuarial fairness (e.g. Baker 1996, 2000; Baker and Simon 2002; Daniels 1990; Heath 2007; Lethonen and Liukko 2011; Radetzki et al. 2008; Stone 1999-2000).

${ }^{3}$ This echoes Joseph Heath's discussion of the scope of political justice (Heath 2006b).

${ }^{4}$ Underwriting is the "process of examining, accepting, or rejecting insurance risks, and classifying those selected, in order to charge the proper premium for each. The purpose of underwriting is to spread the risk among a pool of insureds in a manner that is equitable for the insureds and profitable for the insurer" (Rubin 2008, p. 536) (for a detailed discussion refer to (Anonymized reference)).

5 "The expected value of an act is the sum of the products of such an act (utilities $\times$ probabilities)" (Hacking 2001, p. 80).

${ }^{6}$ This intuition supports positions that claim that insurance is not (or should not be) a redistributive device as expressed by Robert Goodin: "insurance is not fundamentally redistributive at all" (Goodin 1988, p. 159). It can also be found in other works (e.g. Moss 2002, p. 19). 
${ }^{7}$ An externality - or external effect - is a cost (negative externality) or a gain (positive externality) that is suffered (enjoyed) by a third party to an original exchange. This initial and voluntary exchange between two individuals generates an effect that is 'external' in the sense that it is not part of the contract that the third party has not agreed to and that it is not accounted for in the pricing system. In this respect, externalities are cases of market failures (Papandreou 1994).

${ }^{8} \mathrm{~A}$ credit default swap is "a credit derivative structured as a swap. One party is a lender facing a credit risk from a third party and the counterparty in the swap agrees to insure this risk in exchange for regular periodic payments (essentially an insurance premium). If the third party defaults the counterparty insurer will have to purchase from the insured defaulted asset. In turn, the insurer pays the insured the remaining interest on the debt as well as the principal" (Bennett 2004, p. 84).

${ }^{9}$ Risk-shifting (or risk-trading) and risk-pooling mechanisms are two different forms of risk management (Heath 2006a, pp. 323-324; Moss 2002, pp. 92-94). Risk-shifting arrangements, exemplified by CDS, consist in the transfer of risk from one agent to another, while in riskpooling devices (such as insurance), there is no transfer of the risk or its charge. In the latter, policyholders collectively face risks and their material consequences. Risk-shifting mechanisms extract their efficiency by trading risks from risk-adverse agents or agents who have few resources for facing risks to less risk-adverse or more affluent agents. Risk-pooling mechanisms extract their efficiency from the Law of Large Numbers (cf. infra note 14), i.e. the increased statistical reliability implied by the pooling of risk profiles and resources. ${ }^{10}$ For a transfer of costs to be completely fair, some conditions should be met regarding the bargaining conditions that led to the agreement. For instance, A should not be pressured by B to accept the deal. In addition, there are two issues here: one of consent, which is the most important, and another of compensation since some situations where a person suffers some 
additional costs might be fair everything considered because she is compensated despite not having agreed to it. It might be argued that, under certain circumstances, such an arrangement is fair. But, it is not discussed here.

${ }^{11}$ Such a confusion can be found in Kenneth Arrow (Arrow 1963, p. 945) or in Barron's Dictionary of Insurance Terms. Under the entry "insurance", one can find the following definition: "mechanism for contractually shifting burdens of a number of pure risks by pooling them" (Rubin 2008, p. 246, emphasis added).

${ }^{12}$ Expected utility may be objective or subjective, depending on if it includes pure facts or one's conviction. Some prefer the distinction between frequency and belief (Hacking 2001, pp. 127-139). In any case, according to the frequency-type (objective), probabilities are testable, impersonal and based on tendency, propensity and disposition. According to the belief-type, probabilities express a personal or interpersonal view based on confidence and evidence. Except when mentioning that probabilities should be understood from the individual perspective, we use expected utility in an objective fashion, following the frequency-type probabilities.

${ }^{13}$ In other words, if insurance may be seen as redistributive at a given moment in time, it is not redistributive in terms of expected utility.

${ }^{14}$ The Law of Large Numbers is the "mathematical premise stating that the greater the number of exposures, (1) the more accurate the prediction; (2) the less the deviation of the actual losses from the expected losses (X $-x$ approaches zero); and (3) greater the credibility of the prediction (credibility approaches 1). This law forms the basis for the statistical expectation of loss upon which premium rates for insurance policies are calculated" (Rubin 2008, pp. 272-273). In other words, “[a]s the number of trials increases, the accuracy probability approaches 1 ". Then, "[r]elative frequencies tend to converge on probabilities" (Hacking 2001, p. 197). 
${ }^{15}$ We are grateful to Søren Midtgaard for bringing this point to our attention.

${ }^{16}$ Community rating takes place when no differentiation is made among contributors in regard to their risk exposure.

${ }^{17}$ Moral hazard characterizes a "circumstance which increases the probability of loss because of an applicant's personal habits or morals; for example, if an applicant is a known criminal" (Rubin 2008, p. 322).

${ }^{18}$ As evoked below, this objection holds only insofar as risks are choice sensitive. Moreover, moral hazard takes place no matter if premiums are actuarially fair or not. It illustrates the fact that moral hazard is an argument against insurance in general, not against non-actuarial premiums in particular.

${ }^{19}$ The view discussed here introduces individual responsibility in the calculation of the adequate premiums in the sense that fair premiums should reflect one's level of responsibility in regard to the risks covered. It is, however, not the only use of the concept of responsibility. For instance, one may claim that rather than adjusting one's premiums, individual responsibility should be used for drawing a line between insurable (responsibility-insensitive) risks and uninsurable (responsibility-sensitive) ones.

${ }^{20}$ Case C-236/09, Association des Consommateurs Belges Test-Achats ASBL and Others v. Conseil des Ministres (2011).

21 'ECJ gender ruling hits insurance costs', The Guardian, March $1^{\text {st }} 2011$.

${ }^{22}$ For a detailed discussion, refer to Joseph Heath (Heath 2007).

${ }^{23}$ City of Los Angeles Department of Water and Power v. Manhart, 435 U. S. 702 (1978).

${ }^{24}$ This touches upon the broader issue of the quality of the scientific standards used by risk management. 
${ }^{25}$ Economies of scale happen when adding more workers increases the global productivity of the unit of production (e.g. the factory) in a larger proportion than the sum of their individual productivities.

${ }^{26}$ The question of the connection between health insurance and labour mobility revolves around the question of the portability of the rights to health insurance (e.g. Bailey and Chorniy 2013; Holtz-Eakin 1993; Madrian 2004). We are grateful to one anonymous referee for indicating such a connection to us.

${ }^{27}$ A's activities may enhance the situation of other agents, which is a Pareto improvement. However, it might be the case that, due to strict actuarial premiums, by undertaking his activity, and while improving the situation of everyone else, $\mathrm{A}$ is actually worsening his own situation. This advocates for accounting for spillover and external effects in any normative evaluation of insurance and the fairness of its conditions.

${ }^{28}$ One may argue that actuarial premiums are not the problem here, but the fact that a given activity has a spillover effect from which the producer of the activity does not benefit. The distinction would be blatant in the obvious solution of re-internalizing the externalities by transferring additional resources collected by the distant beneficiaries of the positive externalities to their producer. So, premiums could remain determined on a strict actuarial basis whereas beneficial activities could be properly incentivized. However, this kind of measure precisely shows that actuarial premiums are incomplete in the sense that they need to be corrected (or complemented) to be fully fair and efficient. In other terms, actuarial fairness does not encapsulate the complete story of the fairness and efficiency of insurance as a mechanism of social cooperation. 


\section{References}

Ainslie, G. (2001). Breakdown of will. Cambridge University Press, New York.

Ariely, D. (2008). Predictably irrational: The hidden forces that shape our decisions. HarperCollins, New York.

Arrow, K. J. (1963). Uncertainty and the welfare economics of medical care. American Economic Review 53(5), 941-973.

Bailey, J. \& A. Chorniy (2013). Employer-Provided Health Insurance and Job Mobility. (September 23, 2013). Available at SSRN: http://ssrn.com/abstract=2329910 or http://dx.doi.org/10.2139/ssrn.2329910 .

Baker, T. (1996). On the genealogy of moral hazard. Texas Law Review 75(2), 237-292.

Baker, T. (2000). Insuring morality. Economy and Society, 29(4), 559-577.

Baker, T \& J. Simon (eds.) (2002), Embracing risk: The challing culture of insurance and responsibility. Chicago University Press, Chicago.

Bennett, C. (2004). Dictionary of insurance. FT Prentice Hall, Harlow.

Daniels, N. (1990). Insurability and the HIV epidemic: Ethical issues in underwriting. The Milbank Quarterly 68(4), 497-525.

Daniels, N. (2004). The functions of insurance and the fairness of genetic underwriting. In M.

A. Rothstein (ed.), Genetics and life insurance: Medical underwriting and social Policy (pp.119-145). MIT Press, Cambridge, MA.

Dworkin, R. (2002). Sovereign virtue: The theory and practice of equality. Harvard University Press, Cambridge, MA.

Ewald, F. (1986). L'État providence. Grasset, Paris.

Goodin, R. E. (1988). Reasons for welfare: The political theory of the welfare state. Princeton University Press, Princeton, NJ. 
Hacking, I. (2001). An introduction to probability and inductive logic. Cambridge University Press, Cambridge, UK.

Heath, J. (2006a). The benefits of cooperation. Philosophy and Public Affairs 34(4), 313-351.

Heath, J. (2006b). On the Scope of Egalitarian Justice. Les Ateliers de l'Éthique-The Ethics Forum 1(1), 21-41.

Heath, J. (2007). Reasonable restrictions on underwriting. In P. Flanagan, P. Primeaux, \& W. Ferguson (eds.), Insurance ethics for a more ethical world (Research in Ethical Issues in Organizations, Volume 7), (pp.127-159). Emerald Group Publishing Limited, Bingley.

Holtz-Eakin, D. (1993). Is Health Insurance Crippling the Labor Market? Public Policy Brief 10. The Jerome Levy Economics Institute of Bard College, New York.

Hoy, M. and Ruse M. (2005). Regulating genetic information in insurance markets. Risk Management and Insurance Review 8(2), 211-237.

The Guardian (2011). ECJ gender ruling hits insurance costs. March 1.

Kahneman, D. (2011). Thinking, fast and slow. Penguin, New York.

Knight, F. (1921). Risk, uncertainty, and profit. Houghton-Mifflin, Boston.

Lane, W. R. (1997). Discussion of T.A. Moultrie and R.G. Thomas's "The right to underwrite? An actuarial perspective with a difference". Journal of Actuarial Practice $5(1), 141-146$.

Leigh, S. (1998). The freedom to underwrite. In T. Sorell (ed.), Health care, ethics and insurance, (pp.11-53). Routledge, London.

Lethonen, T. K. \& Liukko, J. (2011). The forms and limits of insurance solidarity. Journal of Business Ethics 103(1), 33-44.

Madrian, B. (2004). Health Insurance Portability, Labor Supply and Job Mobility. InterAmerican Conference on Social Security CISS/WP/04012. 
Meyer, R. B. (2004). The Insurer perspective. In M. A. Rothstein (ed.), Genetics and life insurance: Medical underwriting and social policy, (pp.27-47). MIT Press, Cambridge, MA.

Moss, D. A. (2002). When all else fails: Government as the ultimate risk manager. Harvard University Press, Cambridge MA.

Moultrie, T. A. \& Guy T. (1997). The right to underwrite? An actuarial perspective with a difference. Journal of Actuarial Practice 5(1), 125-138.

Papandreou, A. A. (1994). Externality and institutions. Oxford University Press, New York.

Radetzki M., Radetzki M. \& Juth, N. (2008). Genes and Insurance: Ethical, Legal and Economic Issues. Cambridge University Press, Cambridge, UK.

Rawls, J. (1958). Justice as fairness. The Philosophical Review 67(2), 164-194.

Rubin, H. W. (2008). Dictionary of insurance Terms. Barron's, Hauppage.

Rubinstein, A. (1998). Modeling bounded rationality. MIT Press, Cambridge, MA.

Simon, H. (1957). Models of man: Social and rational. Wiley, New York.

Stanovich, K. E. (2009). Decision making and rationality in the modern world. Oxford University Press, New York.

Stone, D. (1999-2000). Beyond moral hazard: Insurance as moral opportunity. Connecticut Insurance Law Journal 6(1), 11-46.

Tversky, A. \& Kahneman, D. (1974). Judgments under uncertainty: Heuristics and biases. Science 185(4157), 1124-1131.

Taleb, N. N. (2008). The black swan: The impact of the highly improbable. Penguin, London. 
Table 1. Actuarial Fairness. Justifications.

\begin{tabular}{|c|c|c|c|}
\hline 1. Cost shifting & \multicolumn{3}{|c|}{ 2. Alteration of the expected utility } \\
\hline $\begin{array}{l}\text { 1.b. Moderate version: Only specific forms of } \\
\text { cost shifting are unfair } \\
\text { Shift of ex ante expected losses is problematic } \\
\text { Unfairness lies in the alteration of the } \\
\text { expected utility of policyholders (which leads } \\
\text { to 2.) }\end{array}$ & $\begin{array}{l}\text { Non-actuarial premiums are } \\
\text { unfair because they are } \\
\text { deceptive } \\
\text { Objection: Deception and } \\
\text { fairness are independent } \\
\text { considerations } \\
\text { Fairness of outcomes: Non- } \\
\text { actuarial premiums cannot be }\end{array}$ & $\begin{array}{l}\text { Non-actuarial premiums are } \\
\text { unfair because they violate } \\
\text { policyholders' expectations of } \\
\text { invariance of the expected } \\
\text { utility } \\
\text { Additional claim: Non- } \\
\text { actuarial premiums accentuate } \\
\text { unfairness by promoting } \\
\text { moral hazard }\end{array}$ & $\begin{array}{l}\text { Non-actuarial premiums are } \\
\text { unfair because individuals } \\
\text { should pay for the losses they } \\
\text { are responsible for } \\
\text { Objection: Responsibility is } \\
\text { not a criterion that determines } \\
\text { the access to or conditions of } \\
\text { insurance coverage }\end{array}$ \\
\hline
\end{tabular}




\begin{tabular}{|l|l|l|l|}
\hline & unfair in this sense & Conclusion: Moral hazard \\
Procedural fairness: Non- & under the form of ex post & variance of probabilities and \\
actuarial premiums might be & unfair in regard to the original \\
terms of cooperation (which & amplitude of losses is an & independent consideration & \\
\hline
\end{tabular}


Table 2. Actuarial Fairness. Objections.

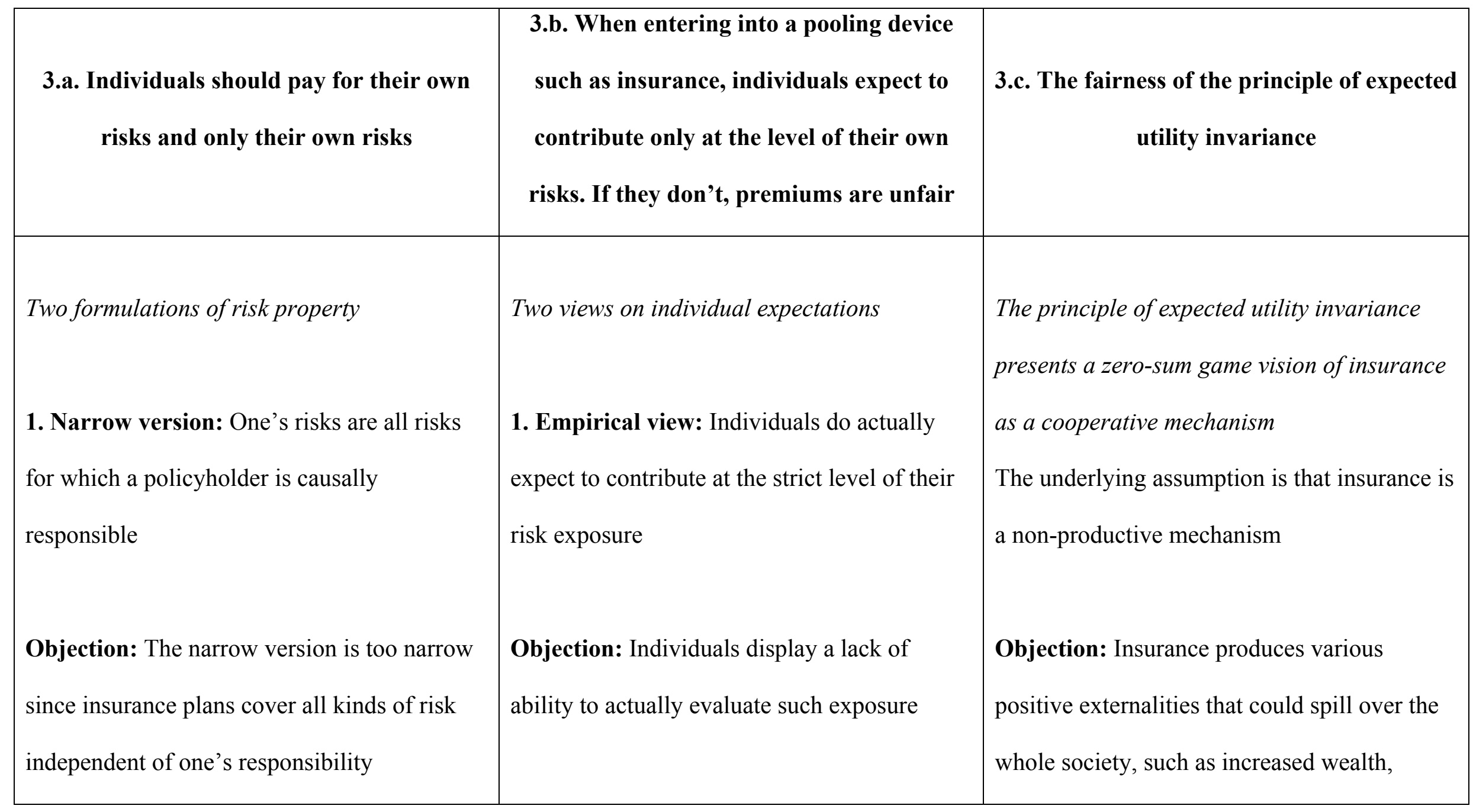




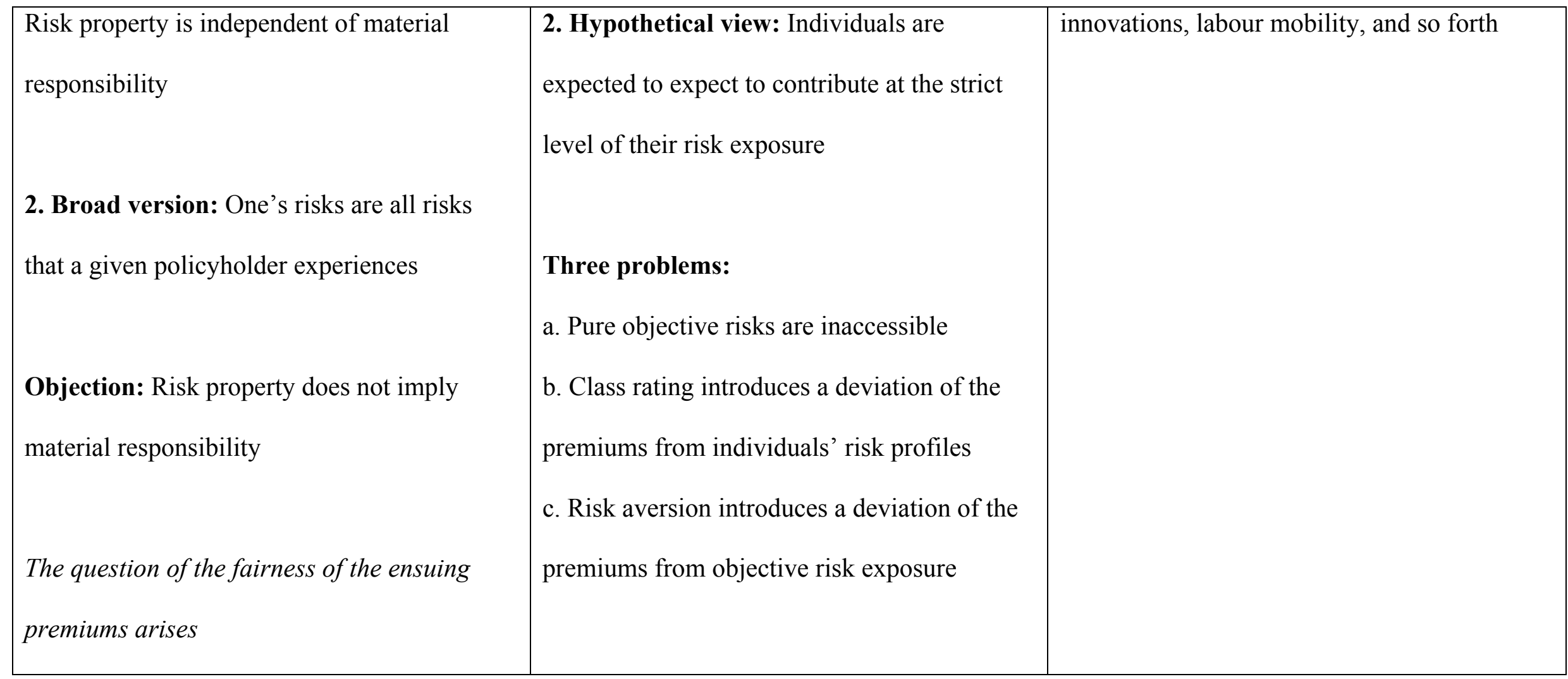

